Jurnal Psikologi Malahayati, Volume 1, No.2, September 2019: 8-17

\title{
EFIKASI DIRI DAN SELF DIRECTED LEARNING READINESS PADA MAHASISWA KEDOKTERAN
}

\author{
Supriyati ${ }^{1}$, Sri Maria Puji Lestari ${ }^{2}$, Eneng Wulandari ${ }^{3}$ \\ 1Program Studi Psikologi, Universitas Malahayati, Bandar Lampung. Email: supriyati@malahayati.ac.id \\ 2,3Program Studi Pendidikan Dokter, Universitas Malahayati, Bandar Lampung.
}

\section{ABSTRACT: SELF EFFICACY AND SELF DIRECTED LEARNING READINESS AMONG MEDICAL STUDENTS}

Nowadays, Medical Faculty uses Problem Based Learning (PBL) method in learning. PBL uses problem or case examples as a triggers to discuss medical learning material. The application of PBL can produce self directed learning readiness (SDLR) in the learning process. SDLR was measured on the basis of an indicator to the extent that a person knows his or her attitudes, skills and personal characteristics to undergo independent learning The application of the SDLR is influenced by two factors, external and internal. One of the internal factors affecting SDLR is Self-efficacy. The purpose of this study was to find relationship between self efficacy and self directed learning readiness among medical students. This study was a quantitative study with analytic design and cross sectional approach. The subject of this study was 185 medical students of Malahayati University grade 2016. The instruments used in this study was general self efficacy scale and self directed learning readiness scale. Based on the data analysis it was found that there is a significant relationship between self efficacy and SDLR among medical student of Malahayati University grade $2016(r=.664, p<.005)$. The result of this study has implication on high education institusion especially medical faculty to build high students' self efficacy and for further research need ti study other factors that relates with SDLR.

\section{Keywords: Self-efficacy, Self Directed learning Readiness, Medical Stidents}

Saat ini Fakultas Kedokteran menggunakan metode belajar Problem Based Learning (PBL). PBL menggunakan masalah atau contoh kasus sebagai pemicu untuk membahas materi pembelajaran kedokteran. Pengaplikasian PBL dapat menghasilkan self directed learning readiness (SDLR) dalam proses belajar. SDLR diukur berdasarkan indikator sejauh mana seseorang mengetahui tetang sikap, keterampilan dan karakteristik pribadinya untuk melaksanakan pembelajaran mandiri. Pengaplikasian SDLR dipengaruhi oleh dua faktor, eksternal dan internal. Salah satu faktor internal yang mempengaruhi SDLR adalah Efikasi diri. Penelitian ini bertujuan untuk meneliti hubungan antara efikasi diri dengan self directed learning readiness pada mahasiswa kedokteran. Jenis penelitian ini adalah kuantitatif dengan desain analitik dan pendekatan cross sectional. Subjek penelitian adalah 186 mahasiswa Fakultas Kedokteran Universitas Malahayati Bandar Lampung angkatan 2016. Alat untuk mengukur efikasi diri yang digunakan adalah General Self Eficacy dan Self Directed Learning Readiness (SDLR). Berdasarkan analisis data ditemukan bahwa terdapat hubungan yang signifikan antara efikasi diri dengan SDLR pada Mahasiswa Fakultas Kedokteran Umum angkatan $2016(r=.664, p<.005)$. Hasil penelitian ini memiliki implikasi pada institusi pendidikan tinggi khususnya fakultas kedokteran untuk membina mahasiswanya memiliki efikasi diri yang tinggi serta untuk penelitian selanjutnya agar meneliti faktor lain yang berhubungan dengan SDLR.

Kata kunci: Efikasi diri, Self Directed Learning Readiness, Mahasiswa Kedokteran 


\section{EFIKASI DIRI DAN SELF DIRECTED LEARNING READINESS PADA MAHASISWA KEDOKTERAN}

\section{PENDAHULUAN}

\section{Problem Based learning (PBL) atau \\ Pembelajaran berbasis masalah digunakan \\ sebagai pemicu untuk membangkitkan rasa \\ ingin tahu dan untuk mengaktifkan pembelajaran \\ sebelumnya. Dalam PBL, masalah bertindak \\ sebagai inisiator pembelajaran (Amin, 2009). \\ PBL pertama kali diperkenalkan pada awal \\ Tahun 1970-an di Universitas Mc Master \\ Fakultas Kedokteran Kanada (Rusman, 2010). \\ Fakultas Kedokteran Universitas Malahayati \\ (UNMAL) sejak Tahun 2008 menjalankan \\ kurikulum baru yaitu Kurikulum Berbasis \\ Kompetensi (KBK) yang disesuaikan dengan \\ Standar Pendidikan Profesi Dokter dengan \\ sistem PBL (Prayoga, 2015). Pengaplikasian \\ PBL dapat menghasilkan self directed learning \\ (SDL) diproses belajar (Gibbons, 2002). \\ SDL adalah peningkatan pengetahuan,} keterampilan, pencapaian, atau pengembangan pribadi yang seseorang pilih dan dilakukan dengan usahanya sendiri dengan menggunakan metode apapun dalam situasi kapanpun (Gibbons, 2002). Dalam evaluasi, peserta didik akan menilai keterampilan baru yang telah mereka dapatkan, apakah jawaban atau solusinya memuaskan, serta kualitas gagasan dan pengetahuan baru sehingga dalam prinsip ini, para siswa bertanggung jawab atas pengalaman belajar mereka sendiri (Leatemia, dkk, 2016). SDLR diukur berdasarkan indikator sejauh apakah seseorang mengetahui tetang sikap, keterampilan dan karakteristik pribadinya untuk menjalani kemandirian belajar disebut dengan Self-Directed Learning Readiness (SDLR) (Fisher, 2001).

Beberapa penelitian telah dilakukan di Fakultas Kedokteran Umum UNMAL untuk meneliti faktor yang mempengaruhi SDLR. Sugianto (2016) telah melakukan penelitian tentang perbedaan SDLR disetiap angkatan. Didapatkan bahwasannya kemampuan tingkat SDLR dapat ditentukan dengan seberapa lama subjek mengikuti jenjang pendidikan kedokteran tersebut. Pada mahasiswa yang berbeda hanya 1 tahun (Tahun Pertama-Tahun Kedua dan Ketiga) juga memiliki perbedaaan, tetapi perbedaan yang ada tergolong tidak signifikan dikarenakan hanya berbeda 1 tahun. (Kusuma, 2016) telah melakukan penelitian tentang Hubungan SDLR dengan stres pada angkatan 2015 FK UNMAL didapatkan mahasiswa yang memiliki kesiapan belajar mandiri yang baik akan tetapi mengalami stres, hal tersebut dapat disebabkan stres yang dialami orang tersebut tidak hanya disebabkan oleh masalah dalam kegiatan perkerjaan diperkuliahan saja, melainkan disebabkan oleh faktor-faktor lain seperti kondisi fisik, lingkungan keluarga, fasilitas, manajemen, waktu, keuangan, motivasi belajar. Dalam penelitian Kusuma pula terdapat mahasiswa yang memiliki kesiapan belajar

Supriyati, Program Studi Psikologi, Universitas Malahayati, Bandar Lampung. Email: supriyati@malahayati.ac.id

Sri Maria Puji Lestari, Program Pendidikan Dokter, Universitas Malahayati, Bandar Lampung Eneng Wulandari, Program Pendidikan Dokter, Universitas Malahayati, Bandar Lampung 


\section{EFIKASI DIRI DAN SELF DIRECTED LEARNING READINESS PADA MAHASISWA KEDOKTERAN}

mandiri yang kurang baik akan tetapi tidak mengalami stres, hal tersebut bisa disebabkan kemampuan penyesuaian diri, cara coping stress ketahanan psikologi, dan kemampuan dalam menghadapi, bertahan, dan mengatasi kesulitan (adversity quotient) yang berbeda pada setiap orang. Berdasarkan wawancara yang dilakukan pada hari Jumat 12 Januari 2018 pada 10 orang mahasiswa/i angkatan 2016 diperoleh bahwa 8 (delapan) orang masih butuh batuan mentor dimana 6 (enam) orang memiliki tingkat kenyakian diri masih redah dan 2 (dua) orang lainnya dikarenakan faktor yang lain. Berdasarkan presurvey diatas didapatkan bahwa Mahasiswa Fakultas Kedokteran Umum UNMAL memiliki SDLR belum maksimal, namun belum dapat dijelaskan lebih lanjut faktor apa saja yang memiliki pengaruh besar terhadap SDLR tersebut.

Pengaplikasian dari metode SDLR dipengaruhi oleh dua faktor yang harus berjalan secara seimbang, meliputi faktor eksternal dan internal. Salah satu faktor internal yang mempengaruhi SDLR adalah Efikasi diri (Bandura, 1994). Efikasi diri adalah kenyakinan bahwa seseorang mampu menjalankan prilaku tertentu atau mencapai tujuan tertentu. Bandura mengatakan bahwa Efikasi diri berpengaruh besar terhadap prilaku. Individu dengan level efikasi diri tinggi lebih mungkin untuk tekun berusaha menguasai tugas pembelajaran ketimbang murid yang level rendah (Ormrod, 2008).

Berdasarkan hasil penelitian Arun dan Nurhalimah (2013), menggambarkan salah satu faktor internal yang mempengaruhi SDLR pada individu adalah self efficacy. Oleh karena itu peneliti tertarik untuk mengetahui hubungan efikasi diri dengan SDLR pada Mahasiswa Fakultas Kedokteran Umum UNMAL.

\section{METODE}

Subjek dalam penelitian ini adalah mahasiswa fakultas kedokteran angkatan 2016 Universitas Malahayati Bandar Lampung. Pemilihan subjek dengan dilakukan dengan cara purposive sample sebanyak 185 subyek, dengan kriteria mahasiswa aktif angkatan 2016, hadir dan bersedia menjadi subyek penelitian.

Penelitian ini merupakan penelitian kuantitatif dengan design penelitian analitik dan pendekatan cross sectional. Alat untuk mengukur efikasi diri yang digunakan adalah General Self Eficacy yang sudah digunakan pada penelitian sebelumnya oleh Masruroh (2017) dan dimodifikasi ulang oleh peneliti. Alat untuk mengukur SDLR menggunakan Self Directed Learning Readiness (SDLR) yang sudah digunakan pada penelitian sebelumnya oleh Kusuma (2016) dan di lakukan modifikasi oleh peneliti. Alat ukur yang telah dimodifikasi dilakukan uji validitas dan reliabilitas diperoleh

Supriyati, Program Studi Psikologi, Universitas Malahayati, Bandar Lampung. Email: supriyati@malahayati.ac.id

Sri Maria Puji Lestari, Program Pendidikan Dokter, Universitas Malahayati, Bandar Lampung Eneng Wulandari, Program Pendidikan Dokter, Universitas Malahayati, Bandar Lampung 


\section{EFIKASI DIRI DAN SELF DIRECTED LEARNING READINESS PADA MAHASISWA KEDOKTERAN}

alat ukur terbukti reliabel baik untuk SDLR $(a=$

.823) dan self efficacy $(\alpha=.836)$.

HASIL

Tabel 1

Distribusi Karakteristik Responden

\begin{tabular}{ccc}
\hline Karakteristik & Frekuensi (n) & Persentase (\%) \\
\hline Jenis Kelamin & & \\
Laki-laki & 69 & $37,3 \%$ \\
Perempuan & 116 & $62,7 \%$ \\
Usia & & \\
$19-21$ & 182 & $98,4 \%$ \\
$22-24$ & 3 & $1,6 \%$ \\
\hline
\end{tabular}

Berdasarkan tabel 1 ditemukan sebagian besar mahasiswa berjenis kelamin perempuan (62.7\%) dan berusia 19-21 tahun (98.4\%)

Tabel 2

Distribusi Tingkat Efikasi diri

\begin{tabular}{ccc}
\hline Tingkat Efikasi Diri & Frekuensi $(\mathbf{n})$ & Presentase \\
\hline Tinggi & 177 & 95,7 \\
Sedang & 8 & 4,3 \\
Rendah & 0 & 0 \\
Total & 185 & 100 \\
\hline
\end{tabular}

Berdasarkan tabel 2, ditemukan bahwa sebagian besar mahasiswa memiliki efikasi diri kategori tinggi (95.7\%).

Tabel 3

Distribusi Tingkat SDLR

\begin{tabular}{ccc}
\hline Tingkat SDLR & Frekuensi (n) & Presentase \\
\hline Tinggi & 185 & 100 \\
Sedang & 0 & 0 \\
Rendah & 0 & 0 \\
Total & 185 & 100 \\
\hline
\end{tabular}

Supriyati, Program Studi Psikologi, Universitas Malahayati, Bandar Lampung. Email: supriyati@malahayati.ac.id Sri Maria Puji Lestari, Program Pendidikan Dokter, Universitas Malahayati, Bandar Lampung Eneng Wulandari, Program Pendidikan Dokter, Universitas Malahayati, Bandar Lampung 


\section{EFIKASI DIRI DAN SELF DIRECTED LEARNING READINESS PADA MAHASISWA KEDOKTERAN}

Berdarsarkan tabel 3, ditemukan bahwa seluruh mahasiswa memiliki SDLR tingkat tinggi (100\%). Sebelum dilakukan uji hipotesis perlu dilakukan uji asumsi berupa uji normalitas. Berdasarkan uji normalitas menggunakan Kolmogorov-Smirnov, ditemukan nilai yang signifikan $(p<.005)$ sehingga dapat dikatakan data tidak terdistribusi normal baik untuk data efikasi diri maupun SDLR. Oleh karena itu, akan dilakukan uji hipotesis berupa uji kolerasi nonparametrik yaitu uji Spearman. Hasil uji kolerasi dapat dilihat pada tabel.4

\section{Tabel 4}

\section{Uji Hipotesis Hubungan Efikasi Diri dan SDLR}

\begin{tabular}{ll}
\hline Variabel & SDLR \\
\hline Efikasi Diri & $0,664^{* * *}$ \\
\hline$n=185$ & \\
$p<.00$ &
\end{tabular}

DISKUSI

Berdasarkan hasil penelitian
didapatkan bahwa mayoritas responden
memiliki tingkat efikasi diri tinggi yaitu sebanyak $95.7 \%$, sedangkan untuk variabel SDLR semua subyek berada pada kategori tinggi dengan frekuensi 185 orang.

Efikasi diri adalah keyakinan bahwa seseorang dapat menguasai sebuah situasi dan hasil menguntungkan (Santrock, 2012). Efikasi diri mempengaruhi pilihan aktivitas mahasiswa. Pada Mahasiswa dengan efikasi diri yang rendah dalam belajar, mungkin menghindari berbagai tugas belajar, khususnya tugas-tugas yang menantang. Mahasiswa yang mempunyai efikasi diri tinggi yakin untuk segera menyelesaikan tugas-tugas belajar. Efikasi diri dapat ditumbuhkan dan dipelajari melalui sumber infomasi utama antara lain, pertama pengalaman keberhasilan, dimana seseorang yang memiliki pengalaman keberhasilan akan menaikkan efikasi individu. Kedua, pengalaman orang lain, dimana keberhasilan orang lain dengan kemampuan yang sebanding dalam mengerjakan suatu tugas akan meningkatkan efikasi diri individu dalam mengerjakan tugas yang sama. Ketiga, persuasi verbal, dimana individu diarahkan dengan saran, nasihat, dan bimbingan sehingga dapat meningkatkan efikasi diri. Individu yang diyakinkan secara verbal cenderung akan berusaha lebih keras untuk mencapai keberhasilan. Sedangkan hal yang dapat menurunkan efikasi diri antara lain pertama, pengalaman kegagalan, seseorang yang memiliki pengalaman kegagalan pada dirinya akan menurunkan tingkat efikasi individu.

Supriyati, Program Studi Psikologi, Universitas Malahayati, Bandar Lampung. Email: supriyati@malahayati.ac.id

Sri Maria Puji Lestari, Program Pendidikan Dokter, Universitas Malahayati, Bandar Lampung Eneng Wulandari, Program Pendidikan Dokter, Universitas Malahayati, Bandar Lampung 


\section{EFIKASI DIRI DAN SELF DIRECTED LEARNING READINESS PADA MAHASISWA KEDOKTERAN}

Kedua, kegagalan orang lain, dimana akan menurunkan penilaian individu mengenai kemampuannya dan individu akan mengurangi usaha yang dilakukan. Ketiga, ketegangan fisik dalam situasi sebagai suatu tanda ketidakmampuan, karena hal itu dapat melemahkan performansi kerja individu. (Ghufron \& Rinawita, 2010). Faktor-faktor yang mempengaruhi perkembangan efikasi diri, diantaranya adalah keberhasilan dan kegagalan pembelajaran sebelumnya, (Ormord, 2006).

Hasil penelitian serupa dengan penelitian yang di lakukan oleh Yuwanto Fakultas Kedokteran Universitas Lambung Mangkuratdengan judulHubungan Efikasi Diri dengan Kesiapan Kerja pada Mahasiswa yang Sedang Mempersiapkan Skripsi, menunjukan bahwa 10 subjek $(20,4 \%)$ memiliki efikasi diri pada kategori sedang, 39 subjek $(79,6 \%)$ memiliki efikasi diri pada kategori tinggi dan hasil penelitian tidak ditemukan hasil efikasi diri yang berada pada kategori rendah. Selain itu penelitian juga di lakukan oleh Rizky dan Zulharman (2014) di Fakultas Kedokteran Universitas Riau dengan judul Hubungan Efikasi Diri dengan Coping Stress pada mahasiswa angkatan 2012 Fakultas Kedokteran Universitas Riau. Hasil penelitian menunjukan bahwa efikasi diri mahasiswa berada paling banyak pada kriteria tinggi sebanyak 60 orang $(56,1)$ sedang 47 orang $(43,9)$ dan kriteria rendah tidak ada.
Hasil penelitian ini sejalan dengan teori Feist \& Feist (2010) mengemukakan bahwa tinggi rendahnya efikasi diri akademik dari subjek bisa di sebabkan salah satunya oleh mastery expereince yang di bentuk dari kegagalan/ keberhasilan masa lalu. Karena karakteristik yang beda-beda dimasa lalu.

Berdasarkan hasil analisis penelitian di dapatkan bahwa semua angkatan 2016 yang menjadi responden memiliki tingkat kategori SDLR tingg. Jumlah pada penelitian ini berjumlah 185 responden dengan tingkat SDLR yang tinggi sebanyak 185 orang dengan presentase 100,0\%. Pada penelitian ini tidak di dapatkan responden yang memiliki SDLR yang sedang maupun yang rendah.

Kesiapan kemampuan belajar mandiri atau SDLR yaitu level seseorang mengenai sikap, kemampuan dan karakteristik pribadi untuk mencapai suatu kemandirian belajar (Rusman, 2012). Kemandirian belajar dapat dilihat dari seberapa besar inisiatif dan tanggung jawab pembelajaran untuk berperan aktif dalam hal perencanaan belajar, pelaksanaan proses belajar, dan evaluasi hasil belajar (Nurhayati, 2016). Pada penelitian yang dilakukan oleh Nyambe, Harsono, dan Rahayu (2016) pada Mahasiswa Fakultas Kedokteran Hasanudin menyatakan bahwa mahasiswa yang memiliki tingkat SDLR yang tinggi adalah mahasiswa yang merasa bahwa belajar itu menyenangkan,

Supriyati, Program Studi Psikologi, Universitas Malahayati, Bandar Lampung. Email: supriyati@malahayati.ac.id

Sri Maria Puji Lestari, Program Pendidikan Dokter, Universitas Malahayati, Bandar Lampung Eneng Wulandari, Program Pendidikan Dokter, Universitas Malahayati, Bandar Lampung 
Jurnal Psikologi Malahayati, Volume 1, No.2, September 2019: 8-17

\section{EFIKASI DIRI DAN SELF DIRECTED LEARNING READINESS PADA MAHASISWA KEDOKTERAN}

belajar itu sebagai hobi, apalagi jika materi pembelajaran tergolong sulit maka mereka tertantang untuk bisa menguasainya. Sedangkan mahasiswa yang memiliki SDLR yang sedang merasa belajar itu sebagai beban sehinga sering mengeluh bila belajar. Keinginan untuk belajar Mahasiswa yang memiliki SDLR yang sedang berasal dari motivasi ekstrinsik seperti ancaman drop out (DO) apabila tidak mencapai batas minimal prestasi belajar yang di syaratkan.

Penelitian Sugiato (2016) dengan judul Perbedaan Tingkat SDLR pada Mahasiswa Tahun Pertama, Kedua, dan Ketiga di Fakultas Kedokteran Universitas Malahayati didapatkan bahwasanya kemampuan SDLR dapat ditentukan dengan seberapa lama subjek mengikuti jenjang pendidikan kedokteran tersebut. Selain itu penelitian juga dilakukan oleh Shadiqin (2016) dengan judul Hubungan Motivasi Belajar dengan TingkatSDLR pada Mahasiswa Pendidikan Sarjana Kedokteran Angkatan 2013 di Universitas Malahayati. Pada penelitian dididapatkan bahwa dari 212 sampel terdapat 191 responden (90.1\%) termasuk kedalam kategori tinggi, dan 21 responden $(9.9 \%)$ termasuk kategori yang rendah. Selain itu Kusuma (2016) melakukan sebuah penelitian dengan judul HubunganSDLRdengan Stres pada Mahasiswa Kedokteran Umum Angkatan 2015. Didapatkan distribusi frekuensi dari 210 sampel responden didapatkan 158 mahasiswa (75.2\%) dengan SDLR baik, dan 52 mahasiswa (24.8\%) dengan SDLR kurang baik.

SDLR dapat dipengaruhi oleh beberapa faktor yaitu faktor yang terdapat didalam dirinya sendiri (internal) dan faktorfaktor yang terdapat dari luar dirinya (ekternal) (Aruan, 2013). Faktor Internal yaitu jenis kelamin, usia, cara belajar, mood dan kesehatan, intelegensi, pendidikan, pengetahuan dasar dan tingkat pengetahuan, sosialisasi dan pengalaman sebelumnya. Faktor Eksternal yaitu waktu belajar, tempat belajar, motivasi belajar, pola asuh orang tua, aksesbilitas sumber belajar, tahun masuk universitas.

Berdasarkan hasil uji statistik spearman diperoleh nilai p $0,000 \quad(<0,05)$ yang berarti terdapat hubungan yang signifikan antara efikasi diri dengan SDLR pada Mahasiswa Fakultas Kedokteran Umum Univertas Malahayati pada angkatan 2016. Dengan nilai kolerasi (r) 0,664 menunjukan kekuatan memenuhi interprestasi 0,6- <0,8 dengan arah kolerasi + (positif) atau searah, semakin tinggi efikasi diri maka semakin tinggi SDLR.

Kesiapan kemampuan belajar mandiri atau SDLR yaitu level seseorang mengenai sikap, kemampuan dan karakteristik pribadi untuk mencapai suatu kemandirian belajar (Rusman, 2012).Salah satu faktor dari SDLR

Supriyati, Program Studi Psikologi, Universitas Malahayati, Bandar Lampung. Email: supriyati@malahayati.ac.id

Sri Maria Puji Lestari, Program Pendidikan Dokter, Universitas Malahayati, Bandar Lampung Eneng Wulandari, Program Pendidikan Dokter, Universitas Malahayati, Bandar Lampung 


\section{EFIKASI DIRI DAN SELF DIRECTED LEARNING READINESS PADA MAHASISWA KEDOKTERAN}

adalah tanggung jawab dalam pembelajaran yang ditandai dengan keuletan dalam belajar dan usaha yang lebih dalam belajar (Knowles, Holton III dan Swanson, 2005) Individu yang bertanggung jawab dalam pembelajarannya akan mengarahkan diri dalam belajar. Menurut Schunk (2012), efikasi diri akademik dapat mempengaruhi banyaknya usaha yang dikeluarkan, keuletan, dan pembelajaran. Efikasi diri adalah keyakinan bahwa seseorang dapat menguasai sebuah situasi dan hasil menguntungkan (Santrock,2012). Zimmerman dan Cleary, (2006) menjelaskan bahwa efikasi diri juga berkaitan dengan tiga proses pembelajaran, yaitu motivasi akademik, pencapaian akademik, dan perkembangan kepribadian. Pada mahasiswa dengan efikasi diri yang rendah dalam belajar, mungkin menghindari berbagai tugas belajar, khususnya tugas-tugas yang menantang. Mahasiswa yang mempunyai efikasi diri tinggi mungkin tidak sabar untuk segera menyelesaikan tugas-tugas belajar. Faktor-faktor yang mempengaruhi perkembangan efikasi diri, diantaranya adalah keberhasilan dan kegagalan pembelajaran sebelumnya. (Ormord,2006).

Penelitian lain dilakukan oleh Fathilla pada tahun (2017) di Fakultas Kedokteran Universitas Lampung dengan judul Hubungan Efikasi Diri Terhadap Self Directed Learnig Readiness Mahasiswa Tahun Pertama Fakultas
Kedokteran Universitas Lampung terbukti bahwa terdapat hubungan antara efikasi diri dengan self directed learnig readiness pada mahasiswa tahun pertama Fakultas Kedokteran Universitas Lampung. Selain itu juga Putri (2015) melakukan penelitian dengan judul Hubungan Efikasi Diri dengan SDLR pada Mahasiswa Program Studi Kedokteran Fakultas Kedokteran Universitas Sebelas Maret Surakarta, hasil uji kolerasi positif dengan SDLR Mahasiswa Program Studi Fakultas Kedokteran Universitas Sebelas Maret Surakarta dengan kekuatan kolerasi sedang. Semakin tinggi efikasi diri mahasiswa, semakin tinggi pula tingkat kesiapan belajar mandirinya. Penelitian ini sejalan dengan teori Bandura (1994) mengungkapkan bahwa pengaplikasian dari metode SDL dipengaruhi dua faktor yang harus sejalan seimbang, meliputi faktor ekternal dan internal. Salah satu faktor internal yang mempengaruhi SDL adalah efikasi diri. Kim \& Park 2011 (dalam Pamungkas 2017) menyarankan untuk meneliti mengenai faktor yang mungkin mempengarui SDL salah satunya efikasi diri akademik. Oleh karena itu, pada penelitian ini didapatkan nilai kolerasi (r) 0,664 menunjukan kekuatan kolerasi yang kuat.

\section{SIMPULAN DAN SARAN}

Berdasarkan dari hasil penelitain dan pembahasan mengenai Hubungan Efikasi Diri

Supriyati, Program Studi Psikologi, Universitas Malahayati, Bandar Lampung. Email: supriyati@malahayati.ac.id

Sri Maria Puji Lestari, Program Pendidikan Dokter, Universitas Malahayati, Bandar Lampung Eneng Wulandari, Program Pendidikan Dokter, Universitas Malahayati, Bandar Lampung 


\section{EFIKASI DIRI DAN SELF DIRECTED LEARNING READINESS PADA MAHASISWA KEDOKTERAN}

dengan SDLR Mahasiswa Fakultas Kedokteran

di Universitas Malahayati maka didapatkan

kesimpulan terdapat Hubungan signifikan antara

efikasi diri dan SDLR pada mahasiswa

kedokteran umum angkatan 2016

Institusi pendidikan diharapkan dapat menjaga dan meningkatkan apa yang sudah dicapai oleh institusi mengenai hasil pencapaian efikasi diri dengan SDLR yang tergolong kategori baik dengan memberikan pelatihan efikasi diri agar lebih siap dalam belajar mandiri serta mampu beradapasi dengan metode pembelajaran Problem Based Learning khususnya di Fakultas Kedokteran Universitas Malahayati. Lebih lanjut, mahasiswa harus menyadari bahwa faktor internal merupakan faktor penting, dalam hal ini efikasi diri harus diakui memiliki peran yang cukup besar dalam meningkatkan SDLR diharapkan mampu untuk melakukan segala keperluan sendiri terutama dalam bidang akademik, agar tidak tertumpu akan teman atau orang lain bahkan dalam konteks ujian. Untuk penelitian selanjutnya diharapkan dapat meneliti faktor lain yang berhubungan dengan SDLR selain efikasi diri.

\section{DAFTAR PUSTAKA}

Amin.Z, Khoo Hoo,(2009). Basics in Medical Education, $\quad 2^{\text {nd }} \quad$ edition, World Sclentific,New Jersey.
Arun, Nurhalimah (2013).Gambaran Kesiapan Self Directed Learning Readiness Pada Mahasiswa Tahap Pendidikan Klinik UIN Syarif Hidayatullah Dan FaktorFaktor Yang Berhubungan.Skripsi.Jakarta.

Bandura A (1994). Self-efficacy. The exercise of control.http:///www.uky.edu/eushe/pajer es/effbook.1.html-diunduh tanggal 15 juni 2015

Dahlan MS (2013). Statistik Untuk Kedokteran Dan Kesehatan :Deskriptif, Bivariat Dan Multivariat Multivariat. Edisi 6. Jakarta: Salemba Medika

Fathilla F, (2017). Hubungan Efikasi Diri dengan Self Directed Learning Readiness Tahun pertama Fakultas Kedokteran Universitas Lampung. Skripsi, FK UNILA, Bandar Lampung

Feist,J \& Fiest G.J (2010) Teori Kepribadian Buku 2 Edisi 7,Jakarta, Salemba Humanika

Fisher M, king J, Tague G (2001). Developemnt Of A Self- Directed Learnig Readiness Scale For Nurse Education. Nurse Education Today,21(7):516-25

Ghufron MN \& Risnawita R(2010), Teori-Teori Psikologi,AR-RUZZ

MEDIA,Maguwoharjo

Gibbons M (2002). The Self Directed Learning Readiness. Vancouver:Wiley

Knowles, M.S., Holton III, E.F., \& Swanson, R.A (2005) The Adult Learner The Definitive Classic In Adult Education \& Human Resourse Development. California. Elsevier

Kusuma.C, (2015) Hubungan Self-Directed Learning Readiness ( SDLR ) Dengan

Supriyati, Program Studi Psikologi, Universitas Malahayati, Bandar Lampung. Email: supriyati@malahayati.ac.id

Sri Maria Puji Lestari, Program Pendidikan Dokter, Universitas Malahayati, Bandar Lampung Eneng Wulandari, Program Pendidikan Dokter, Universitas Malahayati, Bandar Lampung 


\section{EFIKASI DIRI DAN SELF DIRECTED LEARNING READINESS PADA MAHASISWA KEDOKTERAN}

Stres Pada Angkatan 2015. Skripsi, FK UNMAL, Bandar Lampung

Leatemia,Sosilo, \& Berkel,(2016).Self-Directed Learning Readiness of Asia Studensts: Studensts perpective on a Hybrid Problem Based Learning Curriculum.International Journal of Medical Education.

Nurhayati,(2016) Psikologi Pendidikan Inovatif,Pustaka Pelajar,Yogyakarta

Nyambe H, Harsono, Rahayu RG, Hubungan Efikasi Diri dengan Kesiapan Kerja pada Mahasiswa yang Sedang Mempersiapkan Skripsi, Vol 5, No 2, Juli, 2016,Jurnal Pendidikan Kedokteran Indonesia

Ormord JE ,(2006.)Psikologi Pendidikan edisi 6 jilid 2, Erlangga,Jakarta.

Pamungkas SW, Indrawati ES. Hubungan Antara Efikasi Diri Akademik Dengan Self Directed Learning Readiness Pada Mahasiswa Program PGSD Universitas Terbuka Di Wilayah Kabupaten Demak.Jurnal,Vol 6(1) 401-406

Prayoga.Y.E.2015.Ini Sejarah $\begin{array}{r}\text { Fakultas } \\ \text { Universitas }\end{array}$
Kedoketran
Malahayati,Diakses pada 22 Mei
2015(Malahati.ac.id).

Putri, YK,(2015). Hubungan Efikasi Diri dengan Self Directed Learning Readiness pada Mahasiswa Program Studi Kedokteran Fakultas Kedokteran Universitas Sebelas Maret Surakarta. Skripsi, FK UNS, Surakarta

Rizky E \& Zulharman. Hubungan Efikasi Diri dengan Coping Stress pada Mahasiswa Angkatan 2012 Fakultas Kedokteran Universitas Riau,Vol 1, No 2, Oktober,2014,Jurnal
Rusman, (2012). Model-Model Pembelajaran edisi 2,Raja Wali Press,Bengkulu.

Santrock JW (2012),Life - Span Develoment edisi XIII Jilid I ,Erlangga,Jakarta.

Schunk, D.H. (2012). Learning Theories An Educational Perpspective Teori-Teori Pembelajaran : Perspektif Pendidikan Edisi Enam. Yogyakarta, Pustaka Pelajar

Shadiqin, (2016). Hubungan Motivasi Belajar dengan Tingkat Self Directed Learning Readiness pada Mahsiswa Pendidikan Sarjana Kedokteran Angkatan 2013 di Universitas Malahayati. Skipsi, FK UNMAL, Bandar Lampung.

Sugiato, (2016). Perbedaan Tingkat Self Directed Learning Readiness pada Mahasiswa Tahun Pertama, Kedua, dan Ketiga di Fakultas Kedokteran Universitas Malahayati. Skripsi, FK UNMAL, Bandar Lampung

Yuwanto D, Mayangsari MD, Anward $\mathrm{HH}$, Hubungan Efikasi Diri dengan Kesiapan Kerja pada Mahsiswa yang Sedang Mempersiapkan Skripsi, Skripsi, FK Lambung Mangkurat, Banjarmasin Kalimatan

Zimmerman BJ \& Cleary BJ (2006). Adolesecents' Development Of Personal Agency: The Role Of SelfEfficacy Beliefs And Self-Regulatory Skill. Self -Efficacy Beliefs Of Adolescents. Greenwich,CT:Information Age.

Supriyati, Program Studi Psikologi, Universitas Malahayati, Bandar Lampung. Email: supriyati@malahayati.ac.id

Sri Maria Puji Lestari, Program Pendidikan Dokter, Universitas Malahayati, Bandar Lampung Eneng Wulandari, Program Pendidikan Dokter, Universitas Malahayati, Bandar Lampung 